\title{
Tecnologias, aprendizagem da atenção e aprender a estudar
}

\section{Technologies, learning of attention and learning how to study}

\author{
Adriano Rodrigues Ruiz ${ }^{1}$
}

\begin{abstract}
RESUMO
Este artigo relata uma pesquisa bibliográfica que teve por objetivo desenvolver uma reflexão acerca da formação de estudantes autônomos, em um clima rico de informações e de apelos audiovisuais. Três eixos forneceram norte para as argumentações: a abertura de horizontes e de preocupações com as tecnologias de informação e comunicação, tomando por cerne da questão a horizontalidade da comunicação e a possibilidade de coletivos inteligentes; a ressignificação do aprender a estudar, como adequada via de emancipação cognitiva; a centralidade da aprendizagem da atenção, partindo da premissa de que a atenção não se restringe à "condição para a aprendizagem”, podendo ser compreendida como "efeito" de uma aprendizagem. Os eixos percorridos têm como ponto de convergência o autoconhecimento.
\end{abstract}

Palavras-chave: aprendizagem da atenção; aprender a estudar; autoconhecimento.

\begin{abstract}
This article reports a bibliographical research whose objective develops a reflection about training autonomous students in an environment full of information and audiovisual appeal. Three priorities were the focus of our discussion: opening new horizons and issues on information and communication technologies in which the main point is the horizontal communication and the possibility of intelligent networking; the resignification of learning how to study as a way of adequate cognitive emancipation; and the central point of attention learning since attention is not only a "condition to learn",
\end{abstract}

DOI: $10.1590 / 0104-4060.38609$

1 Universidade do Oeste Paulista. Presidente Prudente, São Paulo, Brasil. Rua José Bongiovani, 700 - Cidade Universitária. CEP: 19050-920. 
but it can be understood as "effect" of learning. These priorities converge to self-knowledge.

Keywords: attention learning; learning how to study; self-knowledge.

\section{Introdução}

A questão nuclear deste artigo consiste na busca de mapear um possível caminho que favoreça a formação do aprendiz autônomo, em um mundo rico de recursos tecnológicos, de chamativos convites à distração e do estudar escondido sob a penumbra. Como suporte epistemológico, tomamos as discussões de Varela (2003), ao assegurar que a cognição se estrutura como qualquer outro processo humano, valendo-se da realidade encarnada da existência humana, nos dois sentidos, como estrutura experiencial vivida e como contexto de mecanismos cognitivos.

As Tecnologias de Comunicação e Informação (TIC) povoam um amplo espectro das discussões, ora como ricas fontes de possibilidades, ora como mensageiras de desvios preocupantes. Transitando por essa teia, nesta pesquisa de natureza bibliográfica, estabelecemos como objetivo encaminhar a reflexão acerca da formação de estudantes autônomos em um clima rico de informações e de apelos audiovisuais. Três eixos forneceram norte para nossas argumentações: a abertura de horizontes e de preocupações com as tecnologias; a ressignificação do aprender a estudar; a centralidade da aprendizagem da atenção.

Para situar aberturas, no território das TIC, recorremos a Martin-Barbero (2011) e Pierre Lévy (1996), tomando por cerne da questão a horizontalidade da comunicação e a possibilidade de coletivos inteligentes. A ressignificação do aprender a estudar encontra suporte em pesquisadores como Silva e Sá (1993), que vislumbram nessa aprendizagem uma segura via de emancipação cognitiva. A descoberta de que a atenção não se restringe à "condição para a aprendizagem", podendo ser compreendida como "efeito" de uma aprendizagem, encontra em Virginia Kastrup (2004) referência significativa.

A singularidade desses eixos é convergirem para o autoconhecimento, que pertence ao território de posturas reflexivas, zelosas na arte de ouvir a si mesmo.

\section{As Tecnologias de Comunicação e Informação (TIC)}

As TIC trouxeram ao mundo escolar dois sentimentos não convergentes. O que parece ter sonoridade maior manifesta-se sobre a impaciência dos alunos 
e o outro fala de obstáculos oriundos de um conservadorismo quase que autista da cultura escolar e, ao mesmo tempo, de largas possibilidades de reinvenção dos caminhos da aprendizagem.

Com a presença das TIC, as possibilidades de diferentes aprendizagens se ampliaram. Nas palavras de Martin-Barbero (2011, p. 126), a "escola deixou de ser o único lugar de legitimação do saber, pois existe uma multiplicidade de saberes que circulam por outros canais, difusos e descentralizados". Com isso, a "diversificação e difusão do saber, fora da escola, é um dos desafios mais fortes que o mundo da comunicação apresenta ao sistema educacional". (MARTIN-BARBERO, 2011, p. 126).

Nesse sentido, Martin-Barbero (2011, p. 134) ainda alerta que cabe à educação "ajudar a criar nos jovens uma mentalidade crítica, questionadora da inércia na qual as pessoas vivem". O referido autor assegura, ainda, que a educação ganha significado "à medida que é capaz de desenvolver sujeitos autônomos. Ante uma sociedade que massifica estruturalmente, que tende a homogeneizar". (MARTIN-BARBERO, 2011, p. 134).

Martin-Barbero (2011, p. 134) também identifica a possibilidade de sermos cidadãos como "diretamente proporcional ao desenvolvimento de sujeitos autônomos, isto é, de gente livre, tanto interiormente como em suas tomadas de posição". Pois, é necessário "gente que seja capaz de distanciar-se da arte que está na moda, dos livros que estão na moda; gente que pense com a própria cabeça, e não com as ideias que circulam ao seu redor". (MARTIN-BARBERO, 2011, p. 134).

O autor supracitado alerta que "nada pode prejudicar mais a educação do que nela introduzir modernizações tecnológicas sem antes mudar o modelo de comunicação que está por debaixo do sistema escolar". (MARTIN-BARBERO, 2011, p. 123). Neste ponto reside importante desafio a ser superado, a saber:

[...] o modelo predominante é vertical, autoritário na relação professor-aluno e linearmente sequencial no aprendizado. Enquanto permanecer a verticalidade na relação docente e de sequencialidade no modelo pedagógico, não haverá tecnologia capaz de tirar a escola do autismo em que vive. Por isso, é indispensável partir dos problemas de comunicação antes de falar de meios. (MARTIN-BARBERO, 2011, p. 123).

As teias de comunicação que anulam distâncias e ampliam os coletivos são ofertadas pelo aparato telemático, enquanto isso, a natureza dos vínculos pertence à subjetividade de cada pessoa no jogo intelectual e afetivo do encontro 
de "eus" singulares. As vias telemáticas colocam-nos em um imenso mundo em que o agir e o pensar coletivamente podem se efetivar em horizontes ilimitados, se houver a opção pela comunicação dialógica.

A construção de conhecimentos e de vínculos implica possibilidades para a formação de coletivos inteligentes. Nesse sentido, Lévy (1996, p. 112) aponta que, para esse processo, é necessário aprofundar a abertura da consciência individual "ao funcionamento da inteligência social e melhorar a integração e a valorização das singularidades criadoras que os indivíduos e os pequenos grupos humanos formam nos processos cognitivos e afetivos da inteligência coletiva". Ele acrescenta que, antes "de ser uma lei da história, trata-se de um projeto transmitido, enriquecido, reinterpretado a cada geração e infelizmente suscetível de esclerose ou de esquecimento". (LÉVY, 1996, p. 112).

Lévy (1996, p. 119) ainda lembra que as pessoas são todas inteligentes à sua maneira e que os grupos decepcionam com frequência. Pois, em uma multidão, "as inteligências das pessoas, longe de se adicionar, tendem a se dividir. A burocracia e as formas de organização autoritárias asseguram uma certa coordenação, mas às custas da supressão das iniciativas e do aplainamento das singularidades". O que permite a valorização recíproca das inteligências nos pequenos grupos são "boas regras de organização e de escuta mútua". (LÉVY, 1996, p. 119).

Em suas desafiadoras discussões, uma pergunta que o referido autor formula é: Nossa utopia é a construção de uma sociedade inteligente ou uma sociedade inteligentemente conduzida? Nessa empreitada, dependemos da qualidade dos vínculos que estabelecemos com os outros, se de hierarquia, de submissão, de obediência, nosso caminhar torna-se trôpego e nos perdemos na multidão pouco pensante. Se de escuta, de paciência, de respeito, de atenção e apreço ao diferente, o processo de construção de coletivos inteligentes abre-se para um "vir a ser" povoado de possibilidades ainda não experimentadas.

Lévy (2013) destaca a importância da atenção coletiva, todos os meios midiáticos querem atraí-la:

[...] em vez de ficarmos fascinados por aquele que reclama nossa atenção, essa consciência, é que dá, dentro do espírito coletivo, importância e vida aos atores que a solicitam e às ideias que eles promovem. Ora, em vez de ficarmos fascinados por aquele que reclama nossa atenção, podemos converter nosso olhar em direção ao poder criador que é nossa atenção, nossa consciência, que, na realidade, dirige e cria o mundo humano. (LÉVY, 2013, p. 180). 
Seguindo essa linha, Lévy (2013) afirma que quem governa o mundo é a nossa atenção, porém acrescenta uma pergunta fundamental: Quem governa nossa atenção?

Essa questão merece um olhar atento, pois atinge o núcleo de todo pensamento educacional que pretende ser emancipatório. Envolve claramente o desafio de aprendermos a ouvir a nós próprios.

\section{A centralidade da atenção}

As TIC trouxeram preocupações, pois, o ambiente em que vivemos tem implicações na construção de nossa subjetividade. As exigências do meio sobre as pessoas deixam marcas - hoje merece destaque a sensação de que perdemos bastante da antiga paciência para conversar, estudar, observar as estrelas... Isso tem deslocado as discussões sobre atenção para um lugar de destaque.

Tomamos a atenção assumindo a abordagem enativa, formulada por Varela (1994). De acordo com Sade e Kastrup (2011, p. 140), a enação situa a cognição não como "[...] representação de um mundo prévio por uma mente pré-existente, mas sim pela constituição mútua de si e do mundo através das próprias ações cognitivas, num processo de coemergência". Essas pesquisadoras destacam que: "A atividade de um organismo não é determinada pela informação supostamente captada por ele no ambiente, mas sim pela maneira como ele experimenta a situação, expressa no modo como ele a corporifica". (SADE; KASTRUP, 2011, p. 140).

Buscaremos a centralidade da atenção no lugar apontado por Toro (2010), quando assinala que o grande desafio do ser humano é situar-se e ser no presente, reconhecer os elementos que se modificam e se apresentam além das próprias intencionalidades. Lembrando que a "realidade que se nos apresenta não é tanto aquilo que existe, mas sim aqueles aspectos do mundo nos quais centramos nossa atenção". (WALLACE, 2008, p. 21).

Transitando pelo campo de aberturas para esse tema, encontramos Kastrup (2004, p. 7) que assevera existir, na sociedade contemporânea, “[...] um excesso de informação e uma velocidade acelerada que convoca uma mudança constante do foco da atenção, em função dos apelos que se multiplicam sem cessar".

Essa pesquisadora considera que o anseio pela novidade não permite o tempo requerido para experiências consistentes. Ela esclarece que a distração é um funcionamento em que a atenção vagueia, foge do foco da tarefa e transita por um campo mais amplo, com "pensamentos fora de lugar, percepções sem 
finalidade, reminiscências vagas, objetos desfocados e ideias fluidas, que advêm do mundo interior ou exterior". (KASTRUP, 2004, p. 8).

Kastrup (2004, p. 8) ressalta ser o distraído "[...] alguém extremamente concentrado [...]", com atenção em outro lugar. Zuin e Zuin (2011, p. 224-225), com preocupações semelhantes, afirmam que a "distração concentrada não permite fazer com que o olhar permaneça vinculado à palavra o tempo necessário para que a própria palavra seja tencionada, a ponto de remeter esse olhar para o vislumbre de outros significados". Nesse sentido, "apreender um conteúdo torna-se, mais do que nunca, condição fundamental para que ele possa ser de fato aprendido". (ZUIN; ZUIN, 2011, p. 225).

A subjetividade contemporânea, sob o olhar de Sancovschi e Kastrup (2013), não sofre de falta de foco, mas de excesso de focalização. A atenção saltitante que ganha espaço nas práticas de estudo pode estar relacionada com os dispositivos usados pelos estudantes. "Parece tratar-se de uma captura que prende a atenção e a faz saltar entre focos distintos, impedindo que ela desvie". (SANCOVSCHI; KASTRUP, 2013, p. 199).

Sancovschi e Kastrup (2013, p. 201) asseveram que esse processo pode decorrer do "[...] modo como as novas tecnologias, e em especial o computador-internet, capturam a atenção". Contudo, para essas pesquisadoras, as tecnologias podem auxiliar na "[...] produção da política cognitiva curiosa e desejosa de saber", e isso poderia favorecer a "[...] a produção de novas relações entre estudantes e estudo". (SANCOVSCHI; KASTRUP, 2013, p. 201). Seriam relações mais ligadas ao pensamento que às tarefas.

As pesquisadoras destacam que as tecnologias não são em si positivas ou negativas, elas nos desafiam a investigar os efeitos que produzem sobre a cognição e a subjetividade. Precisamos compreender que, se as tecnologias estão a serviço da execução de tarefas predefinidas e da solução de problemas dados, não contribuem para mudanças de política cognitiva.

Nessa perspectiva, Kastrup, Tedesco e Passos (2008, p. 12) esclarecem que o conceito de política cognitiva procura evidenciar que "o conhecer envolve uma posição em relação ao mundo e a si mesmo, uma atitude, um ethos". Essa compreensão nos afasta da "crença num mundo dado que apenas representamos, que coloca problemas que devemos solucionar". (KASTRUP; TEDESCO; PASSOS, 2008, p. 12). Esses autores discorrem a respeito de duas políticas cognitivas: a da representação e a da invenção do mundo e de si mesmo. A cognição representacional e a cognição inventiva são dois modos de estar no mundo, de estabelecer relação consigo e com a própria atividade de conhecer.

Em uma perspectiva de mudança, sob o olhar de Kastrup (2005, p. 12791280), o aprendizado assume a forma de um círculo, cujo movimento é o de reincidir, retornar, renovar, reinventar, reiterar, recomeçar. A “lógica circular 
do aprender aponta para o inacabamento do processo". O aprendizado torna-se uma sucessão de aprendizagens. "Ele é contínuo e permanente, não se fechando numa solução e não se totalizando em sua atualização, precisando por isso, ser sempre reativado". (KASTRUP, 2005, p. 1280).

Segundo Kastrup (2005), a aprendizagem inventiva inclui a invenção de problemas e revela-se também como invenção de mundo. "Inventar é garimpar algo que restava escondido, oculto, mas que, após serem removidas as camadas históricas que o encobriam, revela-se como já estando lá". (KASTRUP, 2005, p. 1278). A aprendizagem da atenção "[...] é tão necessária à cognição inventiva quanto a aprendizagem da sensibilidade para o músico. Trata-se de afinar o instrumento para, ao tocar, extrair o som mais puro e mais cristalino de um campo sonoro que existia ainda sem atualização". (KASTRUP, 2004, p. 15).

Para a referida pesquisadora, é por ocupar lugar privilegiado que a atenção é tão "visada pela mídia, pela propaganda e pelo mercado". (KASTRUP, 2004, p. 15). Assim,

[...] é tão urgente desvendar seu papel na cognição inventiva e apontar caminhos a serem trilhados através de práticas comprometidas em reativar outras atenções que, fazendo parte de um funcionamento complexo, constituem vias de resistência ao excesso de focalização que nos asfixia no tarefismo fatigante dos dias atuais. (KASTRUP, 2004, p. 15).

Com preocupações convergentes, Nardin e Sordi (2007) esclarecem que

A capacidade atencional, tanto quanto a capacidade de brincar se aprendem; porém, ninguém pode ensiná-las. Isto reveste a função de quem ensina de uma importância singular, já que não existem conteúdos, tampouco métodos que possibilitem estas aprendizagens. Elas somente são possíveis na relação com um outro que acredita na capacidade pensante do sujeito, seja ele criança, jovem ou adulto. (NARDIN; SORDI, 2007, p. 105).

Nardin e Sordi (2007, p. 99) explicam também que "[...] a construção de um espaço de comunicação dialógica favorece a capacidade atentiva dos alunos", pois, espaços dialógicos permitem aos alunos experimentar a aprendizagem da atenção, de modo bem diferente dos ambientes em que os professores transmitem informações e clamam por atenção. 
As referidas pesquisadoras destacam, ainda, que no contexto atual a atenção é vista como "condição para" o sujeito se adaptar às exigências do mundo. Enquanto isso, para a vertente fenomenológica das Ciências Cognitivas tem sido compreendida como "efeito" de uma aprendizagem. Assim, torna-se possível pensar numa ampliação do seu funcionamento e dos mecanismos que a ligam à aprendizagem. (NARDIN; SORDI, 2008).

Nessa perspectiva, as experiências de práticas pedagógicas sustentadas por uma concepção de aprendizagem processual que, fundamentalmente, deve estar apoiada na comunicação dialógica, têm grandes chances de construir uma capacidade de atenção distinta daquela necessária para o ato de receber informação e da qual boa parte dos alunos carece.

Um desafio dessa magnitude não encontra abertura no modelo usual de nossa escola, pois requer a capacidade de problematizar, de inventar - isso só é possível quando se admite outro pensante na relação. Em clima de diálogo em que se aceita a legitimidade do outro se compartilha a diversidade. "Numa cena escolar cotidiana na qual o diálogo está presente, é possível construir um caminho para tratar do sentido como invenção do processo de aprender, em que cognição se mistura à experiência dos cuidados de si próprio". (NARDIN; SORDI, 2008, p. 60).

Nardin e Sordi $(2008$, p. 60) alertam que na "[...] perspectiva de práticas pedagógicas apoiadas na transmissão de informação pode-se pensar na constituição de um determinado modo de atender [...]"; as práticas dialógicas exigem "[...] doses de atenção distintas daquelas que a maioria das crianças e adolescentes experimenta hoje". (NARDIN; SORDI, 2008, p. 60). Essas pesquisadoras enfatizam que é necessário cultivar as duas possibilidades de atenção: a recognitiva e a inventiva, "[...] mas somente a última é capaz potencializar a aprendizagem". (NARDIN; SORDI, 2008, p. 60).

A atenção inventiva permite ao estudante um domínio crescente sobre si mesmo como aprendiz, com destaque para o controle de suas atividades de estudo.

\section{Aprender a estudar}

Aprender a estudar gera múltiplas aberturas ao êxito em empreitadas cognitivas. $\mathrm{O}$ aprender a estudar se constitui com base na compreensão da flexibilidade da inteligência; na tomada de consciência da importância de se estabelecer objetivos e metas; no zelo em cultivar a prática de dar tempo a si mesmo quando diante de desafios cognitivos. 
Aprender a estudar tem natureza emancipatória, abre portas ao autogoverno, quebrando a renitente lógica que sustenta a educação regulada pelo professor e pouco favorável à autonomia dos alunos. Chevallard, Bosch e Gascón (2001) apontam o estudo como elo perdido entre ensino e aprendizagem, disso decorrendo a crença em aprendizagem quase imediata gerada pelas atividades de ensino.

$\mathrm{O}$ estudo sucumbe em um contexto dominado pelo ensino "que parece querer controlar todo o processo didático e uma aprendizagem cada vez mais frágil pela exigência de que seja produzida como consequência imediata, quase instantânea, do ensino". (CHEVALLARD; BOSCH; GASCÓN, 2001, p. IX). O desafio colocado por esses autores "é restituir ao estudo o lugar que lhe é devido: o coração do projeto educativo de nossa sociedade". (CHEVALLARD, BOSCH; GASCÓN, 2001, p. IX).

Nessa linha de raciocínio, "em vez de limitar a educação à interação entre ensino e aprendizagem, propomos considerá-la de maneira mais ampla, como um projeto de estudo cujos principais protagonistas são os alunos". (CHEVALLARD; BOSCH; GASCÓN, 2001, p. IX). Caberia ao professor coordenar o estudo, aos alunos estudar e aos pais ajudar os filhos a estudar e encontrarem sentido para o esforço que lhe é exigido.

Com o estudo no centro do processo, para esses autores, restabeleceríamos a comunicação

[...] entre alunos, pais e professores, fazendo com que o diálogo entre sociedade e escola recupere seu sentido primordial: a escola leva as novas gerações a estudar aquelas obras humanas que melhor lhes servirão para compreender a sociedade na qual estão dispostas a entrar. (CHEVALLARD; BOSCH; GASCÓN, 2001, p. IX).

Percebendo os estudantes nessa busca de compreensão da sociedade, Silva e Sá (1993, p. 71) asseveram que "desenvolver hábitos e estratégias de estudo tem por objetivo final possibilitar ao estudante o acesso a condições e instrumentos mentais, que lhe permitam tornar a sua aprendizagem escolar mais efectiva e autónoma", nesse processo objetiva-se desenvolver competências cognitivas que possibilitem ao estudante maior controle "na realização das suas tarefas escolares. Ao mesmo tempo, procura-se proporcionar o desenvolvimento de sentimentos mais positivos face ao estudo, aumentando os sentimentos de eficácia pessoal e de motivação para a aprendizagem". (SILVA; SÁ, 1993, p. 71).

Para aprender verdadeiramente, Figueiredo e Barros (2012, não paginado) afirmam que é preciso saber aprender. "Saber aprender exige muito do conhe- 
cimento e da reflexão sobre as nossas cognições - metacognição". Os autores escreveram que, em uma perspectiva sociocognitiva, a autorregulação é entendida como um processo conduzido pelos próprios aprendizes que transformam suas capacidades mentais em competências acadêmicas.

$\mathrm{Na}$ construção da inteligência, o autoconhecimento, para Figueiredo e Barros (2012, não paginado), está ligado ao "tempo para ouvir a nós próprios". Os autores alertam para nossa avareza em relação ao tempo que cada pessoa concede a si própria para refletir acerca de seus pensamentos e emoções. "Concedemo-nos mais tempo para pensar os outros, as suas ideias e acções, do que para nos pensarmos a nós próprios". (FIGUEIREDO; BARROS, 2012, não paginado).

Seguindo trajetória similar, Bustingorry e Mora (2008) concebem a metacognição como o conhecimento que a pessoa constrói acerca de seu próprio funcionamento cognitivo. Incluem, nesse quadro, o processo de supervisão e regulação que os sujeitos exercem sobre suas próprias operações cognitivas.

$\mathrm{O}$ autoconhecimento abre caminhos para que pessoas façam as melhores opções quando o assunto for determinar trajetórias de aprendizagem. Silva e Sá (1993) dizem que os sujeitos constroem sobre a inteligência teorias implícitas acerca de si mesmos. Essas teorias tendem a orientar as pessoas, quando acreditam ser a "inteligência um traço fixo tendem a orientar-se para obter avaliações favoráveis desse traço" (SILVA; SÁ, 1993, p. 31), buscando resultados; já que acreditam que "a inteligência é uma qualidade maleável tendem a orientar-se para desenvolver essa qualidade" (SILVA; SÁ, 1993, p. 31), adotando objetivos de aprendizagem.

Silva e Sá (1993, p. 32) asseveram ser necessário "que o sujeito se veja como um agente activo para pôr em marcha os processos cognitivos necessários a um bom desempenho". Nessa perspectiva, a motivação para aprender depende, também, da percepção que o aprendiz possui de suas próprias competências e do controle pessoal "que acredita exercer sobre as actividades escolares". (SILVA; SÁ, 1993, p. 32).

Para isso, é importante que os estudantes compreendam ser a inteligência uma construção conduzida por eles próprios. Nesse sentido, Rosário e Almeida (2005, p. 144) enfatizam que a aprendizagem precisa significar "a apropriação de mecanismos de busca e selecção de informação, assim como de processos de análise e resolução de problemas, que viabilizem a autonomia progressiva do aluno no aprender e no realizar, os quais se prolongam por toda a vida".

Em relação a práticas de ensino dedicadas a fomentar a aprendizagem autorregulada, Alvares e Klimenko (2009) consideram três funções: formar pensadores flexíveis, autônomos e com sentido crítico; desenvolver as habilidades cognitivas e metacognitivas nos estudantes, a fim de que adquiram o senso para orientar-se, buscar, organizar e compreender a informação; basear-se na concepção do conhecimento como algo flexível, pertinente e argumentado. 
Valendo-se de estudos da neurociência cognitiva, Cosenza e Guerra (2011, p. 98) explicam que as funções executivas são responsáveis pela regulação cotidiana ao possibilitarem "nossa interação com o mundo frente às mais variadas situações que encontramos. Por meio delas organizamos nosso pensamento, levando em conta as experiências e conhecimentos armazenados em nossa memória". Em domínios escolares, elas "devem estar voltadas para que os estudantes aprendam a planejar suas atividades, sendo capazes de estabelecer metas". (COSENZA; GUERRA, 2011, p. 98).

O que é necessário é que os alunos "saibam não somente procurar informação utilizando os recursos existentes, mas que saibam, também, identificar as questões relevantes, fazendo inferências e generalizações". (COSENZA; GUERRA, 2011, p. 98). Na atualidade, "nem sempre há um ambiente estruturado de forma adequada para o desenvolvimento das funções executivas. Esse é um problema que deveria ser levado em conta se quisermos realmente educar nossos jovens para uma vida útil e feliz”. (COSENZA; GUERRA, 2011, p. 98).

Cosenza e Guerra (2011) ainda destacam que o cérebro sempre está disposto a processar o que percebe como significante e gratificante, por isso é importante exercer controle sobre a quantidade e a qualidade do que queremos ou devemos processar. Isso é compatível com a perspectiva colocada por Khan (2013, p. 50), ao assegurar que "aprendemos, antes de tudo, decidindo aprender, assumindo compromisso com a aprendizagem, que, por sua vez, gera concentração".

Silva e Sá (1993, p. 64) argumentam que o aluno exerce papel ativo na própria aprendizagem se tiver um objetivo - fruto de uma construção pessoal por ele valorizado, "que o levará a despender esforços e a persistir nas tarefas". Essas pesquisadoras esclarecem que desenvolver hábitos de estudo objetiva "possibilitar ao estudante o acesso a condições e instrumentos mentais, que lhe permitam tornar a aprendizagem escolar mais efetiva e autônoma". (SILVA; SÁ, 1993, p. 71).

Alvares e Klimenko (2009) esclarecem que a organização da atividade de estudo, como processo reflexivo, permite aos alunos a tomada de consciência da presença das habilidades e, também, da necessidade delas no processo de estudo e em situações cotidianas. Isso favorece a construção de condições para o fortalecimento da motivação para buscar novas habilidades.

As referidas autoras asseveram que a ideia de evolução cultural não se limita ao sucesso na obtenção de bons escores nas avaliações escolares, implica avanços por horizontes desconhecidos e contribuições para a transformação cultural. Por sua vez, "essa evolução não se refere apenas ao progresso econômico, tecnológico ou científico da civilização, também abarca o desenvolvimento da dimensão do humano a partir do ser, pensar e atuar em relação a consigo mesmo e com os demais". (ALVARES; KLIMENKO, 2009, p. 12). 
Como esclarecem Jou e Sperb (2006), a metacognição é a capacidade do ser humano ter consciência de seus atos e pensamentos, de pensar o próprio pensar, de desenvolver estratégias para interagir com o meio. Por isso, o olhar atento à educação aberta ao estudo autodirigido possibilita o trânsito por um universo de autonomia com escolhas e significações.

Almeida (2002, p. 163) alerta que temos uma escola ainda pouco apta para intervir e "ajudar os alunos a estudar, a aprender e a pensar". O autor revela acreditar que "a crença atual na modificabilidade cognitiva e a consciência reinante de que a escola deve se preocupar com o ensinar a aprender e a pensar acabarão por introduzir mudanças significativas na lógica funcional e nas práticas escolares". (ALMEIDA, 2002, p. 163).

Em síntese, aprender a estudar implica a tomada de consciência que cabe a cada pessoa a responsabilidade de sua construção como aprendiz autônomo e competente. Contudo, a escola parece ainda renitente quanto a delegar aos alunos espaço de protagonismo.

\section{Algumas considerações}

Em um mundo de complexidade crescente, somos convidados a tecer trajetórias dispondo de áreas de silêncio - aprender a estudar e aprendizagem da atenção - em entrelaçamento com o contexto multiforme e estridentemente chamativo das TIC.

As aprendizagens requeridas para emancipação cognitiva - aprendizagem da atenção e aprender a estudar -, em sua singeleza, não se encaixam no consagrado jargão escolar da transmissão de conhecimentos. Elas requerem um clima de diálogo, de negociações cognitivas e, principalmente, de ouvir a si mesmo.

Esboçamos um desenho em que colocamos em relevo a arte de estudar, apontando o conhecimento acerca do conhecer como abertura de possibilidades para aprendizagens autodirigidas. Trouxemos, também, olhares voltados à aprendizagem da atenção em uma cultura que passeia por múltiplos focos, sem cuidadosas paradas. Completando, encontramos a escola persistindo em sua rota de cultuar o ensino, fundado na transmissão, com isso sua comunicação permanece verticalizada e o protagonismo é dos professores.

Contrapondo-se a isso, há vozes a anunciar possibilidades que se abrem quando experimentamos ouvir a nós próprios, buscando compreender nossos pensamentos e nossas estratégias cognitivas. Ao passear por essas ideias, a compreensão da dimensão do caráter político da forma de concebermos a cognição leva-nos a conceber a possibilidade de culturas de aprendizagem autodirigidas, 
em que as pessoas se inventem como aprendizes e construtoras de sua própria expertise na arte de estudar, conhecendo o seu funcionamento atencional.

Procurando horizontes, entendemos que renovar a forma como nos situamos como leitores do mundo requer a superação da cultura que privilegia tarefas em detrimento de posturas reflexivas. Por esse caminho, a escola seria um lugar de estudos e de exercício de autonomia para conhecer, sem perder de vista o autoconhecimento.

\section{REFERÊNCIAS}

ALMEIDA, L. S. Facilitar a aprendizagem: ajudar aos alunos a aprender e a pensar. Psicologia Escolar e Educacional, Campinas, v. 6, n. 2, p. 155-165, dez. 2002. Disponível em: <http://www.scielo.br/pdf/pee/v6n2/v6n2a06.pdf>. Acesso em: 13 jan. 2012.

ALVARES, J. L.; KLIMENKO, O. Aprender cómo aprendo: la enseñanza de estrategias metacognitivas. Educación y Educadores, Bogotá, v. 12, n. 2, p. 11-28, 2009.

BUSTINGORRY, S. O.; MORA, S. J. Metacognición: un camino para aprender a aprender. Estudios Pedagógicos, Valdivia, Chile, v. 34, n. 1, p. 187-197, 2008.

CHEVALLARD, Y.; BOSCH, M.; GASCÓN, J. Estudar matemáticas: o elo perdido entre o ensino e a aprendizagem. Porto Alegre: Artemed, 2001.

COSENZA, R. M.; GUERRA, L. B. Neurociência e educação. Porto Alegre: Artmed, 2011.

FIGUEIREDO, F. J. C.; BARROS, J. O. Metacognição: tempo para ouvir a nós próprios. 2012. Disponível em: <http://www.ipv.pt/millenium/17_ect10.htm>. Acesso em: 13 maio 2012.

JOU, G. I.; SPERB, T. M. A metacognição como estratégia reguladora da aprendizagem. Psicologia: Reflexão e Crítica, Porto Alegre, v. 19, n. 2, p. 177-185, 2006. Disponível em: <http://www.scielo.br/pdf/prc/v19n2/a03v19n2.pdf>. Acesso em: 25 mar. 2012.

KASTRUP, V. A aprendizagem da atenção na cognição inventiva. Psicologia \& Sociedade, Porto Alegre, v. 16, n. 3, p. 7-16, set./dez. 2004. Disponível em: <http://www.scielo. br/pdf/psoc/v16n3/a02v16n3.pdf>. Acesso em: 20 maio 2013.

KASTRUP, V. Políticas cognitivas na formação do professor e o problema do devir-mestre. Educação \& Sociedade, Campinas, v. 26, n. 93, p. 1273-1288, set./dez. 2005. Disponível em: <http://www.scielo.br/pdf/es/v26n93/27279.pdf>. Acesso em: 23 mar. 2013.

KASTRUP, V.; TEDESCO, S.; PASSOS, E. Políticas da cognição. Porto Alegre: Sulina, 2008 . 
KHAN, S. Um mundo, uma escola - a educação reinventada. Rio de Janeiro: Intrinseca, 2013. LÉVY, P. O ciberespaço e a economia da atenção. In: PARENTE, A. (Org.). Tramas da Rede. Porto Alegre: Sulina, 2013. p. 174-188.

LÉVY, P. O que é o virtual? São Paulo: Editora 34, 1996.

MARTIN-BARBERO, J. Desafios culturais: da comunicação à educomunicação. In: CITELLI, A. O.; COSTA, M. C. C. (Orgs.). Educomunicação: construindo uma nova área de conhecimento. São Paulo: Paulinas, 2011. p. 121-134.

NARDIN, M. H.; SORDI, R. Aprendizagem da atenção e os modos de subjetivação pedagógica e informacional. Psicologia \& Sociedade, Porto Alegre, v. 20, n. 1, p. 53-61, 2008. Disponível em: <http://www.scielo.br/pdf/psoc/v20n1/a06v20n1.pdf>. Acesso em: 13 maio 2014.

NARDIN, M. H.; SORDI, R. Um estudo sobre as formas de atenção na sala de aula e suas implicações para a aprendizagem. Psicologia \& Sociedade, Porto Alegre, v. 19, n. 1, p. 99-106, jan./abr. 2007. Disponível em: <http://www.scielo.br/pdf/psoc/v19n1/a14v19n1. pdf>. Acesso em: 11 maio 2014.

ROSÁRIO, P.; ALMEIDA, L. Leituras construtivistas da aprendizagem. In: MIRANDA, G.; BAHIA, S. (Eds.). Psicologia da Educação: temas de desenvolvimento, aprendizagem e ensino. Lisboa: Relógio D’água, 2005. p. 141-165.

SADE, C.; KASTRUP, V. Atenção a si: da auto-observação à autoprodução. Estudos de Psicologia, Natal, v. 16, n. 2, p. 139-146, maio/ago. 2011. Disponível em: <http://www. scielo.br/pdf/epsic/v16n2/v16n2a04.pdf>. Acesso em: 17 jan. 2012.

SANCOVSCHI, B.; KASTRUP, V. Práticas de estudo contemporâneas e a aprendizagem da atenção. Psicologia \& Sociedade, Belo Horizonte, v. 25, n. 1, p. 193-202, 2013. Disponível em: <http://www.scielo.br/pdf/psoc/v25n1/21.pdf>. Acesso em: 13 jan. 2014.

SILVA, A. L.; SÁ, I. Saber estudar e estudar para saber. Porto: Porto Editora, 1993.

TORO, S. Neurociencias y aprendizaje... texto en construcción. Estudos Pedagógicos, Chile, v. 36, n. 2, p. 313-331, 2010.

VARELA, F. Conhecer: as ciências cognitivas tendências e perspectivas. Lisboa: Instituto Piaget, 1994.

VARELA, F. O reencantamento do concreto. Cadernos de Subjetividade-PUC-SP, São Paulo, v. 1, n. 1, p. 72-86, 2003.

WALLACE, B. A. A revolução da atenção. Petrópolis: Vozes, 2008.

ZUIN, V. G.; ZUIN, A. A. S. Professores, tecnologias digitais e a distração concentrada. Educar em Revista, Curitiba, n. 42, p. 213-228, 2011. Disponível em: <http://www.scielo. br/pdf/er/n42/a14n42.pdf>. Acesso em: 12 maio 2012.

Texto recebido em 19 de novembro de 2014.

Texto aprovado em 17 de março de 2015. 